\title{
LA DEFENSORÍA DEL PUEBLO. LA EXPERIENCIA PERUANA
}

\author{
SAMUEL B. ABAD YUPANQUI ${ }^{1}$ \\ Catedrático de Derecho Constitucional \\ Pontificia Universidad Católica del Perú
}

\author{
SUMARIO \\ I. La Defensoría del Pueblo en la Constitu- \\ ción peruana de 1993. \\ II. La Ley Orgánica de la Defensoría del \\ Pueblo. \\ III. El funcionamiento de la Defensoría del \\ Pueblo. \\ IV. Reflexiones finales.
}

La figura del Ombudsman aparece en América Latina a partir de la década de los noventa, aunque con algunos antecedentes, con denominaciones distintas como Defensor del Pueblo, Procurador de los Derechos Humanos, Defensor de los Habitantes o Comisionado Nacional de los Derechos Humanos. Su tardía recepción puede explicarse por diversos factores, entre los que es posible señalar lo escaso y reciente de los estudios en castellano sobre dicha institución, la reducida difusión de esta figura, la complejidad de la expresión Ombudsman que no es explicativa de sus alcances, y su escaso engarce con la tradición jurídica de nuestros países². Así, ha sido introducida en países como Guatemala (1985), Brasil (1986 en el Estado de Paraná), México (1990), El Salvador (1991), Colombia (1991), Costa Rica (1992), Paraguay (1992), Honduras (1992), Perú (1993), Argentina (1993), Bolivia (1994), Nicaragua (1995), Ecuador (1996), Panamá (1996) y Venezuela (1999).

1 Ha sido Adjunto (1996-2005) y Primer Adjunto (2005-2007) de la Defensoría del Pueblo del Perú. Doctor en Derecho por la Universidad Autónoma de Madrid.

2 FIX ZAMUDIO H.,"Posibilidad del Ombudsman en el Derecho Latinoamericano", La Defensoría de los Derechos Universitarios de la UNAM y la institución del Ombudsman en Suecia, UNAM, México, 1986, págs. 34-35). 
A este impulso han contribuido organizaciones que han surgido con la finalidad de promover la introducción del Ombudsman en los países de América Latina. Una de ellas es el Instituto Latinoamericano del Ombudsman-Defensor del Pueblo (creado en 1983), y que surgió "con el objeto de coordinar los esfuerzos dedicados al estudio, promoción y creación del Ombudsman en los distintos países de América Latina "3, Asimismo, la Asociación Iberoamericana del Ombudsman-Defensor del Pueblo (1992), uno de cuyos objetivos esenciales fue precisamente "promover la difusión e institucionalización del Ombudsman o Defensor del Pueblo en Iberoamérica". Posteriormente, se creó la Federación Iberoamericana del Ombudsman (FIO) (1995), a fin de fomentar las relaciones de cooperación entre los defensores iberoamericanos, fortalecer la cultura de los derechos humanos, apoyar la promoción del Ombudsman en los países de la región, entre otros aspectos. A nivel mundial, destaca el Instituto Internacional del Ombudsman (IOI), creado en 1978 y que agrupa a todos los Ombudsman del sector público. Asimismo, los Defensores del Pueblo de la región andina se agruparon y crearon en 1998 el Consejo Andino de Defensores del Pueblo, cuyo objeto, es estrechar la cooperación entre las Defensorías andinas, apoyar la incorporación en los países que aún no cuentan con dicha institución y difundir sus actividades.

Este conjunto de esfuerzos, han contribuido a resaltar la importancia de contar con una institución de esta naturaleza a nivel supranacional, siguiendo iniciativas de países europeos ${ }^{4}$. Fue así que el Parlamento Andino, en su IX período de sesiones, dispuso la creación de un Defensor del Pueblo Andino a través de la decisión 483/IX de 24 de septiembre de 1992. Conforme a dicha resolución, la Mesa Directiva aprobará el estatuto, el presupuesto y designará al Defensor del Pueblo que se encargará de la defensa de los derechos humanos en la subregión andina.

De otro lado, a nivel de Naciones Unidas se viene desarrollando un importante trabajo sobre las denominadas ainstituciones nacionales de protección y promoción de los derechos humanos", una de las cuales es, precisamente, la Defensoría del Pueblo. En esta dirección, en 1991, el Centro de Derechos Humanos de Naciones Unidas organizó un primer encuentro, en el que se propuso a los gobiernos que incluyeran en sus legislaciones internas determinados principios generales adoptados con motivo de tal reunión ${ }^{5}$.

Esto fue ratificado en la Declaración y Programa de Acción de Viena, aprobada por la Conferencia Mundial de Derechos Humanos en 1993, al so-

3 HOCHMAN I., "El Instituto Latinoamericano del Ombudsman", en Capitulo Boliviano del Ombudsman, Ombudsman, Democracia y Derechos Humanos, La Paz, Bolivia, 1991, págs. 214215.

4 «El Tratado de Constitución de la Unión Europea, prevé la existencia de la institución del Ombudsman o Defensor del Pueblo en el seno de la Unión" (GIL ROBLES A.,El Defensor del Pueblo y su impacto en España y América Latina", Revista de la Asociación Iberoamericana del Ombudsman-Defensor del Pueblo, n. ${ }^{\circ}$ 3, Colombia, 1994, pág. 58).

5 Cfr. Documento de la Comisión de Derechos Humanos de Naciones Unidas E/CN.4/1992/43, 16 de diciembre de 1991, págs. 52-56. 
licitarse que "se creen o refuercen instituciones nacionales, teniendo en cuenta los "Principios relativos al estatuto de las instituciones nacionales", reconociendo que cada Estado tiene derecho a elegir el marco que mejor se adapte a sus necesidades nacionales específicas" (parágrafo 36).

De esta manera, puede apreciarse que en el plano internacional, existe una fuerte y activa corriente que viene promoviendo la introducción de instituciones de esta naturaleza en los países de América Latina, pues constituye una señal positiva de que se vienen dando los pasos necesarios para garantizar los derechos de las personas y fortalecer la institucionalidad democrática.

Perú no ha permanecido ajeno a estas influencias. Así, la Constitución de 1979 otorgó algunas funciones de defensoría del pueblo al Ministerio Público, mientras que la Constitución de 1993, optó por modificar la anterior situación incorporando la Defensoría del Pueblo como órgano autónomo (artículos 161 y 162).

En los momentos actuales, la Defensoría del Pueblo cuenta con casi tres lustros de funcionamiento —oficialmente inició sus actividades el 11 de septiembre de 1996 - y el reto consiste en cumplir con eficacia y transparencia sus funciones de defensa y promoción de los derechos de las personas, tratando de mantener y superar la credibilidad obtenida en sus inicios.

\section{LA DEFENSORIA DEL PUEBLO EN LA CONSTITUCIÓN PERUANA DE 1993}

\section{ANTECEDENTES}

La Asamblea Constituyente (1978-1979) convocada para elaborar una nueva Constitución introdujo como novedad una función adicional al Ministerio Público. En efecto, el Proyecto de Constitución elaborado por la Comisión Principal de Constitución de dicha Asamblea dispuso en el artículo 260 inciso 4 que correspondía al Ministerio Público «actuar como defensor del pueblo ante la administración pública ${ }^{6}$. Esta propuesta fue formulada por un constituyente pues el proyecto inicial no la contemplaba ${ }^{7}$.

De esta manera, el artículo 250 inciso 4 de la Constitución de 1979 estableció que correspondía al Ministerio Público aactuar como defensor del pueblo ante la administración pública». Su titular era el Fiscal de la Nación, funcionario designado por el Presidente de la República, con aprobación del Senado (artículo 251, inciso 2).

6 Comisión Principal de Constitución de la Asamblea Constituyente 1978-1979, Diario de los Debates, Tomo III, pág. 202.

7 «El señor Valle Riestra.- (...) Esas serían las grande vías maestras de la discusión que podríamos tener hoy. (...) , y si se mantiene la Fiscalía del Perú como una figura autónoma, independiente del Poder Judicial, con atribuciones de Defensor del Pueblo, (...)", Sesión del 05 de febrero de 1979. Comisión Principal de Constitución de la Asamblea Constituyente 1978-1979,Diario de los Debates, Tomo V, pág. 247. 
A fin de implementar estas funciones se efectuaron diversos esfuerzos, destacando la expedición de la Resolución 192-89-MP-FN de 27 de abril de 1989 que creó la llamada Fiscalía Especial encargada de los asuntos de Defensoría del Pueblo y Derechos Humanos. Durante el segundo semestre de 1990, se crearon once Fiscalías Especiales de Defensoría del Pueblo y Derechos Humanos en el interior del país en los departamentos de Ancash, Ayacucho, Huánuco, Piura, Apurímac, Callao, Junín, San Martín, Arequipa, Huancavelica y la Libertad 8 .

La labor del Ministerio Público en el ejercicio de funciones de Defensoría del Pueblo, pese al esfuerzo de quienes trabajaron en la Fiscalía Especial, quedó rebasada ante la difícil situación que atravesaba en esos momentos el país debido al incremento del terrorismo (Sendero Luminoso, Movimiento Revolucionario Túpac Amaru). Además, desde otra perspectiva, resultaba incongruente que el órgano estatal titular de la acción penal -y en consecuencia de acusar a las personas - sea a la vez él encargado de defenderlas.

De ahí que la Constitución de 1993, haya optado razonablemente por modificar la anterior situación al incorporar a la Defensoría del Pueblo como órgano autónomo (artículos 161 y 162), disponiendo que le corresponde "defender los derechos constitucionales y fundamentales de la persona y de la comunidad; y supervisar el cumplimiento de los deberes de la administración estatal y la prestación de los servicios públicos a la ciudadanía". De esta manera, al Ministerio Público ya no le compete esta función.

\section{Incorporación de la Defensoría del Pueblo en la Constitución DE 1993}

El proceso de elaboración de la Constitución de 1993, actualmente vigente, se caracterizó por carecer de un anteproyecto o texto base sobre el cual pudiera centrarse la discusión. La Carta fue elaborada paulatinamente por la Comisión de Constitución y Reglamento, y luego elevada al Pleno del Congreso Constituyente Democrático (CCD) para su aprobación.

Aun cuando algunas ideas previas fueron expuestas por las agrupaciones que llegaron a formar parte del CCD, ninguna de las principales reformas constitucionales anunciadas por la alianza oficialista "Nueva Mayoría-Cambio 90" se refería a la introducción de la Defensoría del Pueblo.

Fue durante el debate de las atribuciones del Ministerio Público realizada en la $40^{a}$ sesión de la Comisión de Constitución y Reglamento realizada el 6 de abril de 1993, donde se planteó el debate sobre la conveniencia de mantener fusionado al Ministerio Público con la Defensoría del Pueblo o separar a ambos órganos como instituciones autónomas.

8 CHAVEZ VALDERRAMA C.,"La Defensoría del Pueblo en el Perú", Lecturas sobre Temas Constitucionales 6, Lima: CAJ, 1990, págs.157-164. 
La propuesta de contar con un Defensor del Pueblo autónomo fue formulada, entre otros, por los congresistas Fernando Olivera (Frente Independiente Moralizador - FIM), Carlos Ferrero y César Fernández Arce, ambos de la agrupación oficialista Nueva Mayoría - Cambio 90 (41ª Sesión de la Comisión de Constitución) y, finalmente, fue aceptada. De esta manera, se logró separar las funciones atribuidas al Defensor del Pueblo de las que correspondían al Ministerio Público, acordándose conformar una subcomisión integrada por los citados congresistas y Lourdes Flores (Partido Popular Cristiano) para elaborar un texto alternativo sobre el Defensor del Pueblo. En la $42^{a}$ sesión realizada el 12 de abril el articulado propuesto por dicha subcomisión fue aprobado con algunas modificaciones? .

A lo largo del debate constitucional, el texto fue reducido en cuanto al número de artículos hasta que la institución quedó perfilada tal como lo señala la actual Carta fundamental, vigente desde el 31 de diciembre de 1993.

\section{Diseño COnStitucional}

La Defensoría del Pueblo (artículos 161 y 162) ha sido configurada como un órgano constitucional autónomo e independiente, distinto del Ministerio Público, al que le corresponden las siguientes funciones básicas: defender los derechos constitucionales y fundamentales de la persona y la comunidad; supervisar el cumplimiento de los deberes de la administración estatal; y supervisar la prestación de los servicios públicos a la ciudadanía.

El Defensor realiza investigaciones y presenta informes anuales al Congreso y cada vez que éste lo solicite. Asimismo, está dotado de iniciativa en la formación de leyes, gozando de legitimación para la interposición de la acción de inconstitucionalidad, tal como lo dispone el artículo 203 inciso 3) de la Constitución. Los órganos públicos tienen la obligación de colaborar cuando él lo requiera. Su proyecto de presupuesto se presenta al Poder Ejecutivo y el propio titular lo sustenta ante esa instancia y en el Congreso.

Cabe anotar, que la Constitución distingue la Defensoría del Pueblo, del Defensor del Pueblo quien es el titular de la misma, señalando que su estructura en el ámbito nacional se establecerá por una ley orgánica. En consecuencia, al legislador le corresponde diseñar la presencia de la Defensoría a nivel nacional, en el marco de un Estado unitario pero descentralizado.

El Defensor del Pueblo es elegido y removido por el Congreso de la República mediante una votación calificada de dos tercios del número legal de miembros. No se encuentra sujeto a mandato imperativo, goza de la prerrogativa de la acusación constitucional antes de acudir al Poder Judicial, así como de inmunidad e inviolabilidad. Para ser elegido se requiere tener 35

9 Congreso Constituyente Democratico, Diario de los Debates de la Comisión de Constitución y Reglamento, Tomo III, págs.1670 y ss. 
años y ser abogado; tiene las mismas incompatibilidades que los vocales supremos. El cargo dura cinco años y es posible la reelección.

Su nombramiento por el Congreso resulta razonable y se explica por ser éste el representante de la soberanía popular que le brinda legitimidad democrática para actuar. Sin embargo, la experiencia ha demostrado las dificultades para llegar a un consenso que permita alcanzar los votos necesarios. Así por ejemplo, luego de la renuncia del Primer Defensor del Pueblo, el Dr. Jorge Santistevan de Noriega, pasaron casi cinco años para que el Congreso pudiera elegir a su sucesor.

\section{LA LEY ORGANICA DE LA DEFENSORIA DEL PUEBLO}

\section{ANTECEDENTES}

Los primeros días de enero de 1994, el congresista Carlos Ferrero, entonces perteneciente a la agrupación oficialista Nueva Mayoría-Cambio 90, presentó al Congreso de la República un proyecto de ley orgánica de la Defensoría del Pueblo ${ }^{10}$

El texto fue debatido en una audiencia pública realizada en el Congreso de la República el 23 de marzo del mismo año, siendo aprobado por la Comisión de Justicia el 14 de abril. Dicho proyecto, fue elevado al Pleno del Congreso y debatido el 4 de mayo de 1994. En tal ocasión, se acordó diferir su discusión por espacio de una semana. No obstante, el acuerdo no se cumplió, pues sólo después de un año el proyecto volvió a ser sometido a debate.

En efecto, esto sucedió el 5 de mayo de 1995; en tal ocasión el proyecto fue aprobado por el Congreso. Sin embargo, días después, el 11 de mayo, el Pleno aceptó el pedido de reconsideración formulado por el congresista Enrique Chirinos Soto (perteneciente al Movimiento Renovación, cercano al gobierno), disponiendo que el texto aprobado sea nuevamente revisado. De esta manera, sucedió algo insólito, los mismos congresistas que inicialmente habían aprobado el proyecto ahora lo "desaprobaban". Se demostró así una falta de voluntad política por dotar al país, en breve plazo, de una ley que regule la estructura y funcionamiento de la Defensoría del Pueblo.

Ante esta extraña situación, diversas instituciones se pronunciaron a favor de la aprobación del proyecto de ley. Entre ellas, podemos mencionar a los decanos de los Colegios de Abogados del país, al Colegio de Abogados de Lima, a la Coordinadora Nacional de Derechos Humanos y a la Comisión Andina de Juristas. Asimismo, diversos medios de comunicación en sendos editoriales exigieron la pronta aprobación de la ley y cuestionaron la demora en implementar esta institución.

10 Publicado en el diario oficial "El Peruano" el 10 de enero de 1994. 


\section{LAS CRÍTICAS AL PROYECTO DE LEY}

Durante el debate en el Pleno del Congreso, se sostuvo que el proyecto convertiría al Defensor del Pueblo en un "Superpoder", un "gran inquisidor", generaría una enorme burocracia, afectaría la defensa y seguridad nacional y convertiría al Perú en un país ingobernable ${ }^{11}$.

Incluso, Carlos Torres y Torres Lara, entonces Presidente de la Comisión de Constitución del Congreso, perteneciente a la agrupación oficialista Nueva Mayoría - Cambio 90, sostuvo que el artículo 16 del proyecto, que desarrollaba el deber constitucional de cooperación de las autoridades y funcionarios para facilitar la labor del Defensor, "llega a una situación de extremismo" pues lo faculta a solicitar informaciones, declaraciones y realizar inspecciones en los servicios públicos y establecimientos de las Fuerzas Armadas, Policía Nacional y Centros Penitenciarios o cualesquiera entidades estatales sometidas a su control.

Tales cuestionamientos carecían de sustento alguno. Diversas razones lo demuestran.

a) Una de las notas que definen a la institución del Ombudsman o Defensor del Pueblo es precisamente contar con «amplios poderes para solicitar todo tipo de información, a fin de faciltarles su labor ${ }^{12}{ }^{2}$. Así por ejemplo, en Alemania, el Ombudsman militar puede "solicitar información oral o escrita a cualquier miembro de las fuerzas armadas, inclusive al ministro federal de defensa; tener acceso a los expedientes, a menos que a ello se opongan poderosas razones de secreto; (...) visitar las unidades, estado mayor u oficina administrativa de las fuerzas armadas en el momento que el Ombudsman lo considere apropiado y sin aviso previo", entre otras facultades ${ }^{13}$. En consecuencia, resultaba absurdo considerar que las facultades de investigación y solicitud de información del Defensor del Pueblo podían hacer colapsar a las Fuerzas Armadas.

b) El Defensor no es un "superpoder", está sujeto a control funcional y presupuestal. El Congreso, que según la Constitución lo nombra por mayoría de dos tercios, podrá cesarlo si considera que actúa negligentemente y decidirá si lo dota del presupuesto que solicita. Y esto, tampoco es una novedad: en la mayoría de países que cuentan con esta institución así sucede. No se trata pues de un órgano que carezca de control.

c) Su labor no afecta la seguridad o defensa nacional. El artículo 17 del proyecto de ley establecía expresas restricciones tratándose de casos debidamente justificados en cuestiones relativas a la seguridad, defensa nacional o a

11 Las mayores críticas las formuló el entonces congresista Enrique Chirinos Soto muy cercano a la agrupación del expresidente Fujimori, quien defendió su posición en el Congreso y divulgó a través de un artículo publicado en el diario "El Comercio", Lima, 21 de junio de 1994, pág. $\mathrm{A} / 2$.

12 VENEGAS ALVAREZ S., Origen y devenir del Ombudsman, una institución encomiable, UNAM, México 1988, pág. 44.

13 VENEGAS ALVAREZ S., Ob. Cit. pág.46. 
relaciones internacionales, siempre que ello sea acordado por el Consejo de Ministros.

d) El Defensor del Pueblo no dicta sentencias, no impone multas ni sanciones. El cumplimiento de sus recomendaciones y sugerencias se basa en el "convencimiento" ${ }^{14}$, en la persuasión basada en el prestigio y calidad morales de quien desempeña el cargo. Como indica la doctrina, se trata de una "magistratura de la persuasión".

En realidad, lo sucedido evidenció que existieron quienes quisieron aprobar una ley que implemente a un débil Defensor del Pueblo. Como el proyecto dotaba al Defensor de facultades que no agradaban — v.g. ingresar a los cuarteles militares- se optó por modificarlo.

\section{Alcances De LA LEY}

La Ley N. ${ }^{\circ} 26520$, publicada el 8 de agosto de 1995 , pese a las críticas y recortes que sufrió ha permitido contar con una institución tutelar de los derechos humanos en el Perú.

Ella desarrolla las atribuciones que los artículos 161 y 162 de la Constitución le asignan: defender los derechos constitucionales de la persona y de la comunidad; supervisar el cumplimiento de los deberes de la administración estatal así como la adecuada prestación de los servicios públicos.

En términos generales se trata de una positiva ley, inspirada tanto en la experiencia de la Fiscalía Especial de Defensoría del Pueblo y Derechos Humanos como en la legislación de otros países no sólo europeos - especialmente de España - sino también de América Latina. La ley configura a la Defensoría del Pueblo del modo siguiente:

a) Órganos de la institución: El Defensor del Pueblo, quien es el titular de la Defensoría del Pueblo. Asimismo, los Adjuntos al Defensor del Pueblo, los cuales representan al Defensor del Pueblo en el ejercicio de sus funciones y atribuciones, y son seleccionados mediante concurso público por un período de tres años (artículo 7). El Defensor designa al Adjunto que lo representará en caso de impedimento temporal o cese, cuando le sea imposible continuar en el cargo, hasta que lo asuma el sucesor (artículo 8).

b) Facultades del Defensor: Inicia y prosigue, de oficio o a pedido de parte, investigaciones frente a los excesos de la Administración estatal o de sus agentes, incluyendo a las personas jurídicas no estatales que ejerzan prerrogativas públicas y la prestación de servicios públicos por particulares. Está legitimado para interponer las acciones de inconstitucionalidad, hábeas corpus, amparo, hábeas data, acción popular y acción de cumplimiento en defensa de los derechos constitucionales. Además, puede intervenir en los procesos de hábeas corpus para coadyuvar a la defensa del perjudicado. Inicia o

14 FAIREN GUILLEN V., ob. cit., pág.51. 
participa, de oficio o a pedido de parte, en cualquier procedimiento administrativo en defensa de los derechos de las personas. Tiene iniciativa legislativa. Promueve la firma, ratificación, adhesión y difusión de los tratados sobre derechos humanos Dicta los reglamentos que faciliten el cumplimiento de sus funciones. Elabora informes que anualmente presenta al Congreso y, además, cuando la situación así lo exige (informes especiales). Asimismo, elabora Informes y Resoluciones Defensoriales sobre temas de especiales trascendencia. La ley no alude en forma expresa a la función mediadora y conciliadora, así como a la labor de promoción y difusión de los derechos humanos. Sin embargo, consideramos que es consustancial a la Defensoría del Pueblo desarrollar este tipo de labor ${ }^{15}$. Además, buena parte de su labor es de orientación y también puede intervenir en el sistema interamericano presentando denuncias e informes de amicus curiae.

c) Organización: La Defensoría contará progresivamente con oficinas en cada capital de departamento. Además, podrá establecer otras en los lugares que estime necesario (artículo 33). El Defensor del Pueblo puede designar libremente a los asesores necesarios para el ejercicio de sus funciones (artículo 34).

d) Procedimiento: La ley ha establecido un determinado procedimiento (artículos 20 y ss.) que se inicia con la presentación de las quejas, y continúa con la evaluación de su admisibilidad, la solicitud del informe al funcionario público o institución contra quien ella se formula, la resolución del caso y, si la situación lo amerita, la formulación de recomendaciones. A esto se une la posibilidad de llevar a cabo acciones inmediatas en los casos que se estime conveniente, por ejemplo, una inspección a una Comisaría ante la denuncia de una detención arbitraria. Por lo demás, el Defensor está facultado para dictar «las normas complementarias para la tramitación de las quejas que a su juicio requieran de acción inmediata", estableciendo distintos procedimientos en función de las atribuciones con que cuenta la Defensoría (artículo 9 inciso 7). Ello ha permitido que en la actualidad, como veremos más adelante, cuente con un "Protocolo de Actuaciones Defensoriales".

\section{La Defensoría del Pueblo y las Fuerzas Armadas}

La Ley eliminó toda mención expresa hacia las Fuerzas Armadas. Sin embargo, ella — como toda norma - tiene vida propia, independientemente de la intención del legislador, y autoriza una interpretación conforme a la Constitución, que permita al Defensor una intensa fiscalización respecto a la actuación de las Fuerzas Armadas.

a) Ello, pues, su misión constitucional es precisamente "defender los derechos constitucionales y fundamentales de la persona y la comunidad", labor

15 Así suele ocurrir en América Latina. Cfr. SANTISTEVAN DE NORIEGA J.,"El Defensor del Pueblo en Iberoamerica", Comentarios a la Ley Orgánica del Defensor del Pueblo, VVAA, Madrid: Defensor del Pueblo, Aranzadi, 2002, pág. 965. 
que no puede ser obstaculizada por las Fuerzas Armadas. b) Además, las Fuerzas Armadas forman parte de la administración estatal; como afirma Fernando López Ramón «la única caracterización posible de las Fuerzas Armadas reside en afirmar su inserción en la Administración del Estado ${ }^{16}$. En consecuencia, su funcionamiento por expreso mandato constitucional deber ser supervisado por el Defensor. De ahí que, mal puede pensarse que aquel encuentra un límite frente a ellas. c) Incluso, el propio artículo 29 de la Ley dispone que "durante los estados de excepción el Defensor del Pueblo, en cumplimiento de su función constitucional, podrá sugerir a las autoridades administrativas, judiciales o militares", las medidas que deben ser revocadas o modificadas en forma inmediata. Si la ley le permite intervenir sobre tales autoridades durante la vigencia de un régimen de excepción, con mayor razón debe autorizarlo en circunstancias normales. d) A diferencia de otros países donde existe un ombudsman militar especializado en estos temas - tal como ocurre en el ordenamiento australiano, alemán, israelí o noruego-, consideramos que el Perú ha seguido el modelo español otorgándole dicha función al propio Defensor del Pueblo ${ }^{17}$.

No obstante, debemos reconocer que más allá de lo que pueda establecer la ley o una interpretación de la misma, el adecuado funcionamiento de la institución dependerá del tipo de Defensor que designe el Congreso. Un Defensor independiente y comprometido con la promoción y defensa de los derechos humanos y los valores democráticos permitirá saltar las posibles limitaciones de la ley en aras del respeto de su misión constitucional cual es la "defender los derechos constitucionales y fundamentales de la persona y de la comunidad" (artículo 162). El primer Defensor del Pueblo desde el inicio de sus funciones reconoció su competencia en esta materia y así lo evidenció en sus actuaciones.

En efecto, esta situación se ha podido apreciar desde un principio pues, para citar un ejemplo, cuando se han presentado quejas por reclutamientos arbitrarios realizados por las Fuerzas Armadas, es decir, incumpliendo lo dispuesto por la Ley del Servicio Militar, la Defensoría del Pueblo ha intervenido para obtener la libertad de las personas —incluso menores de edad- ingresando a los cuarteles y exigiendo a las autoridades militares competentes su liberación. Cierto es que ello era mucho más difícil durante el régimen autoritario del Ing. Alberto Fujimori pues en tal ocasión las Fuerzas Armadas se mostraban reticentes a las intervenciones defensoriales e incluso negaban este tipo de conductas.

16 LOPEZ RAMON Fernando, "La caracterización jurídica de las Fuerzas Armadas", Madrid: CEC, 1987, pág.376.

17 PEÑARRUBIA IZA Joaquín María,"Ombudsman militar y Defensor del Pueblo. Estudio de Derecho Comparado y español", Madrid: Editorial Dilex, S.L., 2001, págs. 107-108. 


\section{EL FUNCIONAMIENTO DE LA DEFENSORIA DEL PUEBLO}

\section{La elección del primer Defensor del Pueblo y las dificultades para SU SUCESIÓN}

En marzo de 1996 el Congreso eligió como Defensor del Pueblo al Dr. Jorge Santistevan de Noriega, quien había sido propuesto por la Comisión Especial presidida por el entonces congresista Carlos Torres y Torres Lara, de conformidad con el artículo 3 de la Ley Orgánica de la Defensoría del Pueblo. Alcanzó una importante votación en el Congreso de la República pues obtuvo noventa y cinco votos favorables de los ciento diez congresistas presentes en la sesión; sólo tuvo seis votos en contra, ocho en blanco y uno viciado ${ }^{18}$.

A esta elección contribuyó el hecho que fuera un candidato de consenso que no venía del oficialismo ni de la oposición. El nombramiento de una persona que ofrecía credenciales que lo acreditaban como un profesional independiente generó fundadas expectativas respecto al desarrollo de una nueva y desconocida institución incorporada por la Constitución de 1993.

Luego de su designación y posterior juramento ante el Congreso de la República, el Defensor del Pueblo formó un reducido equipo de trabajo y un plan básico para que la institución en un plazo de seis meses pudiera iniciar la atención de las quejas que se presenten. Este tiempo se dedicaría a diseñar la institución, convocar al personal necesario, elaborar los reglamentos internos, contar con el presupuesto necesario y, en definitiva, implementar una institución nueva cuyo único antecedente era una dependencia que formaba del Ministerio Público. Ciertamente, esto no significó que durante estos seis meses no se recibieran algunas quejas que la Defensoría tuvo que atender. En este sentido, destacó la intervención con motivo de la venta de acciones de la Telefónica del Perú a ahorristas a través de un sistema de participación ciudadana que motivó que el Defensor formule puntuales recomendaciones que finalmente fueron acogidas.

En noviembre del 2000, el Defensor del Pueblo, antes de culminar su mandato de cinco años, renunció al cargo para intentar postular a la Presidencia de la República por una agrupación política, encargando la conducción de la institución a su Primer Defensor Adjunto, el Dr. Walter Albán Peralta. La Resolución Defensorial N. ${ }^{\circ}$ 66-2000/DP, le encomendó las funciones de Defensor del Pueblo, y a la vez remitió al Presidente del Congreso de la República, la renuncia formulada. Cabe recordar, a manera de comparación, que la ley del Defensor del Pueblo de Bolivia señala en su artículo 9 que «El Defensor del Pueblo no podrá postular a cargos electivos durante los cinco

18 Congreso de La República, Diario de los Debates, Segunda Legislatura Ordinaria de 1995, 4 Sesión, jueves 28 de marzo de 1996, pág. 188.

El primero de abril se publicó en el diario oficial "El Peruano" la Resolución Legislativa N. ${ }^{\circ}$ 26584 a través de la cual el Congreso de la República formalizaba la elección del primer Defensor del Pueblo del Perú. 
años posteriores al cese de sus funciones». La ley peruana no regula este supuesto $^{19}$.

El Primer Adjunto encargado de las funciones de Defensor del Pueblo, desarrolló esta labor por espacio de casi cinco años. En su momento postuló al cargo de Defensor del Pueblo pero el Congreso no pudo obtener el consenso necesario para elegirlo. Debido a las dificultades para proceder a una elección al no alcanzarse los votos necesarios, el Congreso modificó el artículo 3 de la Ley Orgánica de la Defensoría del Pueblo, a través de la Ley N.º 27831, publicada el 21 de setiembre de 2002. Dicha ley estableció que si no se lograba alcanzar la mayoría de dos tercios, por acuerdo del Pleno del Congreso se podría efectuar una convocatoria complementaria para elegir al Defensor del Pueblo por invitación.

En septiembre de 2005 el Congreso eligió a la Dra. Beatriz Merino Lucero como nueva Defensora del Pueblo. El procedimiento de elección fue distinto al seguido para elegir al primer Defensor del Pueblo, pues en esta ocasión el Congreso acordó invitarla a postular. El mismo día la candidata propuesta envió una comunicación por fax aceptando la invitación formulada, pues se encontraba en ese momento en Washington D.C. trabajando en el Banco Mundial. Efectuada la votación fue elegida por noventa y dos votos a favor, dos en contra y una abstención, lo cual se formalizó a través de la Resolución Legislativa N. ${ }^{\circ}$ 007-2005 publicada en el diario oficial el 30 de septiembre $^{20}$. Se trataba de una conocida abogada que, entre otros cargos, había tenido una activa participación en la vida política del país, pues había sido senadora por el partido FREDREMO (1990-1992), congresista por el Frente Independiente Moralizador (1995-2000) y Presidenta del Consejo de Ministros designada por el Presidente Toledo del Partido Perú Posible (2003). En este año, 2010, vence el período por el que fue designada y habrá que ver cómo se presenta la situación en el Congreso para lograr el consenso necesario que permita elegir al próximo Defensor del Pueblo.

\section{TRES ETAPAS DISTINTAS: LA IMPORTANCIA DEL CONTEXTO PARA DEFINIR la AGENDA DE una DeFENSORÍA}

En el Perú es posible referirnos a tres etapas distintas de la Defensoría del Pueblo en función del momento que le tocó vivir. Veamos:

a) La Defensoría del Pueblo durante el régimen autoritario del ex-Presidente Alberto Fujimori, época en la cual el Primer Defensor del Pueblo fue el

19 "Sería conveniente incluir un dispositivo que evite que la persona designada como defensor pueda postular a un cargo político en un determinado plazo luego de su cese. De esta manera, se estaría evitando que se pueda utilizar el cargo de defensor con aspiración política partidaria" (Comision Andina de Juristas, Defensoría del Pueblo. Análisis comparado, Lima, 1996, pág.44).

20 Congreso de la República, Diario de los Debates, Primera Legislatura Ordinaria de 2005, $11^{\text {a }}$ Sesión, jueves 29 de setiembre de 2005, pág.641. 
Dr. Jorge Santistevan de Noriega (abril 1996 - diciembre 2000) y donde fue la única institución pública autónoma pues todas las restantes fueron copadas por el gobierno. Ello le permitió actuar críticamente frente a los abusos del poder gubernamental y adquirir una legitimidad impresionante.

b) La Defensoría del Pueblo en una etapa de transición luego de la vacancia del cargo de Presidente de la República declarada por el Congreso de la República ante la renuncia del Ing. Alberto Fujimori efectuada por fax desde el Japón. En esta etapa cumplió una labor trascendente el Defensor del Pueblo encargado el Dr. Walter Albán Peralta (diciembre 1996 - noviembre 2005), quien como hemos mencionado fue el Primer Adjunto designado por el Dr. Jorge Santistevan y asumió la conducción de la institución ante su renuncia.

c) Y, finalmente, la Defensoría del Pueblo en un contexto democrático, a cargo de la Dra. Beatriz Merino, que ha privilegiado temas de diversa naturaleza, como por ejemplo la supervisión de políticas públicas, el seguimiento y evaluación de los conflictos sociales, la lucha contra la corrupción y la necesidad de afianzar un buen gobierno. En esta etapa, a diferencia del momento inicial, las restantes instituciones públicas actúan con independencia lo cual favorece su labor, situación que no se presentaba en la etapa inicial.

De esta manera, la experiencia demuestra que el contexto de un determinado país es importante para definir la agenda de temas y líneas de trabajo que una Defensoría debe priorizar para cumplir cabalmente su misión. En regímenes autoritarios los espacios de intervención de esta institución se reducen pero pueden dar resultados siempre que su titular actúe con la suficiente autonomía e independiente frente al poder.

\section{Desarrollo institucional y eStructura orgánica}

El 11 de setiembre de 1996, la Defensoría del Pueblo inició su atención al público. Para ello, contaba con un equipo inicial básicamente en la ciudad de Lima y un reducido presupuesto.

La estructura orgánica inicial de la Defensoría del Pueblo contaba, luego del Defensor del Pueblo, con un Primer Defensor Adjunto, una Oficina de Protección o de Atención de Quejas, un Programa de Supervisión de Penales y dos defensorías especializadas en Derechos de la Mujer y Asuntos Constitucionales. Posteriormente, se fueron abriendo oficinas en el interior del país a las que se denominó, en ése momento, Representaciones Defensoriales.

Luego de algunos años de funcionamiento, esta estructura cambió y se optó por sustituir la Oficina de Protección y crear tres Adjuntías en materia de Derechos Humanos, Administración Estatal y Servicios Públicos, respectivamente. Asimismo, se mantuvieron las dos defensorías especializadas que posteriormente fueron denominadas Adjuntías. Además, en ese momento se contaba con tres programas especiales: Asuntos Penales y Penitenciarios, Co- 
munidades Nativas, y Protección a las Personas Afectadas por la Violencia Política.

Posteriormente, en la que hemos denominado tercera etapa de la Defensoría, se crearon dos nuevas Adjuntías: la Adjuntía para la Niñez y la Adolescencia, y la Adjuntía para la Prevención de Conflictos Sociales y la Gobernabilidad. De esta manera en la actualidad, la estructura orgánica de la Defensoría es la siguiente: a) Defensor del Pueblo. b)Primer Adjunto. c)Adjuntías (siete): Adjuntía para los Derechos Humanos y las Personas con Discapacidad; Adjuntía para los Derechos de la Mujer; Adjuntía del Medio Ambiente, Servicios Públicos y Pueblos Indígenas; Adjuntía en Asuntos Constitucionales; Adjuntía para la Administración Estatal; Adjuntía para la Niñez y Adolescencia; y la Adjuntía para la Prevención de Conflictos Sociales y la Gobernabilidad. d)Programas adscritos a las Adjuntías (siete): Programa de Protección de Derechos en Dependencias Policiales; Programa de Defensa y Promoción de las Personas con Discapacidad; Programa de Asuntos Penales y Penitenciarios (adscritos a la Adjuntía para los Derechos Humanos y las Personas con Discapacidad); Programa de Pueblos Indígenas (adscrito a la Adjuntía del Medio Ambiente, Servicios Públicos y Pueblos Indígenas); Programa de Descentralización y Buen Gobierno; Programa de Identidad y Ciudadanía (adscritos a la Adjuntía para la Administración Estatal); y, finalmente, el Programa de Ética Pública, Prevención de la Corrupción y Políticas Públicas (adscrito a la Adjuntía para la Prevención de Conflictos Sociales y la Gobernabilidad).e) Oficinas Defensoriales (veintiocho): Paulatinamente se fue creciendo contándose en la actualidad con presencia a nivel nacional. En efecto, la Defensoría cuenta con veintiocho Oficinas Defensoriales, a cargo de un Jefe de Oficina, y diez Módulos de Atención que dependen de las citadas Oficinas en todo el país.

Para desarrollar a cabalidad sus funciones la Defensoría del Pueblo requería del presupuesto público (Recursos Ordinarios) necesario. Además, desde el inicio de sus actividades contó con el importante apoyo de la Cooperación Internacional (Donaciones y Transferencias). Hay que destacar que el presupuesto total se ha elevado progresivamente en los últimos años.

Cabe indicar que durante el gobierno de Fujimori era muy difícil que el Poder Ejecutivo y el Congreso pudieran dotar a la Defensoría de un presupuesto público razonable, pues precisamente ello fortalecería a una institución autónoma encargada de supervisar los excesos del poder. Por ello, el aporte de la Cooperación Internacional durante esta etapa fue sumamente importante, llegando a alcanzar casi el 50\% del presupuesto total de la institución. Como puede apreciarse en un contexto democrático esta situación ha cambiado sustancialmente.

\section{LOS CASOS Y LAS ESTRATEGIAS DE ACTUACIÓN DEFENSORIAL}

A lo largo de su funcionamiento, la Defensoría del Pueblo ha ido adquiriendo importantes niveles de legitimidad y credibilidad debido a su marcada 
autonomía frente al poder y su contribución en la solución de los conflictos presentados. Ello se ha visto reflejado en el incremento anual de los casos llegados a su conocimiento, así como en las diversas encuestas de opinión realizadas que evidenciaban el importante nivel de aprobación de la institución.

Asimismo, para mejorar su atención al público en los últimos años la Defensoría del Pueblo ha fortalecido sus instrumentos de gestión y supervisión. En este sentido, ha elaborado un "Protocolo de Actuaciones Defensoriales" —aprobado mediante Resolución Administrativa N. . 047-2008/DP-PAD, de 15 de agosto del 2008-, cuya finalidad es modernizar y agilizar los procedimientos de actuación de casos por parte de la institución para poder brindar un servicio más ágil y oportuno.

De acuerdo con el citado "Protocolo" las actuaciones defensoriales se clasifican en quejas, petitorios y consultas: a) La queja es "toda solicitud que requiere la intervención de la Defensoría del Pueblo alegando la vulneración o el peligro de vulneración de un derecho constitucional o fundamental debido a la actuación u omisión de una entidad de las administraciones públicas, de la administración de justicia o de las empresas prestadoras de servicios públicos" (Artículo 21). b) El petitorio es "toda solicitud que requiere la intervención de la Defensoría del Pueblo a manera de buenos oficios para que atienda y/o solucione una situación de indefensión que afecta o amenaza sus derechos fundamentales, que no se derivan de una actuación u omisión de una entidad de las administraciones públicas, de la administración de justicia o de las empresas prestadoras de servicios públicos pero que esta puede atender en ejercicio de sus competencias" (Artículo 52). c) La consulta es "toda solicitud de información y consejo planteada a la Defensoría del Pueblo, sobre asuntos jurídicos, de índole institucional, de apoyo social o psicológico, que no implican la afectación a derechos fundamentales y/o respecto a los que la Defensoría del Pueblo no resulta competente" (Artículo 63).

Cabe indicar que los pedidos de intervención defensorial no sólo se efectúan por escrito o personalmente en las diversas oficinas de la institución, sino además a través de su Centro de Atención Virtual que permite recibir quejas, petitorios y consultas por teléfono o a través del correo electrónico.

Conforme lo indica el último Informe Anual presentado al Congreso el año 2010 que da cuenta de las actuaciones defensoriales realizadas durante el año 2009 (enero-diciembre), el número de casos atendidos paulatinamente se ha ido incrementando de forma ciertamente significativa.

Además, la Defensoría del Pueblo elabora tres tipos de informes. Por un lado, los Informes Anuales que se presentan y sustentan ante el Congreso de la República, de otro lado los Informes Extraordinarios que se presentan cuando así lo solicita el Congreso y finalmente los informes temáticos conocidos en el Perú como Informes Defensoriales y que son los más numerosos ${ }^{21}$. Estos últimos, a julio de 2010, son 151 y todos ellos pueden consultarse en su

21 DONAYRE PINEDO M., La magistratura de la persuasión: Los informes del Defensor del Pueblo de España (1983-1987) y de Perú (1998-2002), Palestra, Lima, 2006. 
página web. Con estos informes la Defensoría no sólo rinde cuenta de su actuación sino a la vez aporta con sus puntuales recomendaciones a la marcha del Estado y al respeto de los derechos fundamentales.

Una situación presente en los diversos Informes Anuales ha sido constatar que la institución más quejada suele ser la Oficina de Normalización Provisional (ONP), institución encargada de tramitar y conceder pensiones. Se trata de un tema de atención defensorial permanente debido a la conducta de dicha institución que actúa en forma engorrosa y con criterios destinados, lamentablemente, a negar la concesión de pensiones. Por ello, ha sido necesario que la Defensoría plantee propuestas de reforma, tal como sucedió en el Informe Defensorial N. ${ }^{\circ} 135$ "Por un acceso justo y oportuno a la pensión: Aportes para una mejor gestión de la ONP."

Finalmente, se ha elaborado el "Defensómetro" con la finalidad de medir la eficiencia de la Defensoría en cuanto a la admisión y conclusión de quejas, así como el cumplimiento del deber de cooperación por parte de las entidades del Estado. "Su objetivo primordial es monitorear la gestión de la Defensoría del Pueblo en el ámbito nacional, por medio de sus cuatro indicadores: eficiencia en la admisión de quejas, eficiencia en la conclusión de quejas, cooperación con información sustentada y eficacia en la solución de hechos vulneratorios. Los reportes mensuales y rangos de resultados en porcentaje permiten hacer un seguimiento, a fin de tomar medidas preventivas y correctivas para mejorar la gestión defensorial en la atención de las quejas presentadas ${ }^{22}$.

Esta instrumento de gestión facilita el monitoreo tanto a nivel interno como externo de la actuaciones defensoriales.

\section{Temas priorizados por la Defensoría del Pueblo}

A lo largo de estos catorce años de funcionamiento, la Defensoría del Pueblo ha abordado diversos casos y problemas de trascendencia general, que pueden ser examinados con detenimiento en los trece Informes Anuales publicados hasta el momento y que pueden consultarse en su página web (www.defensoria.gob.pe). Una apretada síntesis, que se limitará a examinar diez temas puntuales, y que no pretende agotar todos los aspectos abordados por la Defensoría puede ser la siguiente:

\subsection{Liberación de inocentes y personas privadas de la libertad}

Un primer tema que motivó la intervención de la Defensoría fue cuando presidió la Comisión Ad-Hoc de indultos. En efecto, para enfrentar el fenómeno terrorista, el gobierno del Ingeniero Alberto Fujimori dictó un conjunto

22 Defensoría del Pueblo, Décimo Tercer Informe Anual de la Defensoría del Pueblo al Congreso de la República enero - diciembre 2009, pág. 32. 
de dispositivos, especialmente luego del golpe de Estado del 5 de abril de 1992, que privilegiaron como alternativa el incremento de la represión penal (incorporando la cadena perpetua), el juzgamiento de civiles por tribunales militares, el procesamiento por jueces "sin rostro" —es decir, no identificados por sus nombres sino por claves-, el fortalecimiento de las atribuciones policiales, y en general el debilitamiento del derecho de defensa y del debido proceso en su conjunto. En definitiva, se privilegió una reacción básicamente penal que diluía el debido proceso bajo el argumento que era la mejor manera de enfrentar al fenómeno terrorista y sancionar a los culpables. Todo ello estuvo contenido en el Decreto Ley N. ${ }^{\circ} 25475$, que regulaba el delito de terrorismo, y en el Decreto Ley N. ${ }^{\circ} 25659$ sobre traición a la patria o terrorismo agravado.

La aplicación de tales decretos leyes propició un elevado número de errores judiciales, lo que trajo como consecuencia la existencia de una cifra importante de personas inocentes en prisión. Esto explica que en un afán de sana rectificación la Ley N.o 26655 haya creado la Comisión Ad-Hoc, presidida por el Defensor del Pueblo, encargada de proponer al Presidente de la República el indulto de quienes habían sido injustificadamente procesados o condenados por estos delitos. Se trató de una solución particular, pues en ese contexto la alternativa de que la Corte Suprema pudiera revisar todos los procesos en los que existían errores judiciales era realmente inviable. Cabe anotar que desde la creación de la Comisión Ad-Hoc presidida por el Defensor del Pueblo hasta su finalización en diciembre de 1999, más de quinientas personas fueron indultadas o se les concedió el derecho de gracia. Este fue el primer tema que le permitió ir adquiriendo legitimidad a la entonces nueva institución.

De otro lado, la Defensoría supervisa la vigencia de los derechos de las personas privadas de la libertad. A partir de ello, ha podido verificar que el sistema penitenciario en el Perú adolece de una crisis de carácter crónico, debido a que los diferentes gobiernos no han contado con un diseño adecuado de política penitenciaria, que pueda responder a los problemas que afectan a estas personas.

En efecto, la Defensoría del Pueblo ha encontrado en el desarrollo de su trabajo que los problemas se derivan de los escasos recursos que se destinan a la atención del sistema penitenciario y a una sobrecriminalización que ha caracterizado a las medidas adoptadas en materia de política criminal. Estas medidas son a su vez causa del hacinamiento carcelario, los deficientes servicios penitenciarios y la vulneración de derechos fundamentales a la población penitenciaria.. Por ello, la Defensoría en sus informes ha declarado la existencia de un "estado de cosas inconstitucional" al existir una afectación permanente a los derechos de los detenidos, que lamentablemente hasta el momento no ha sido superada. 


\subsection{Verdad y lucha contra la impunidad}

La lucha contra la impunidad constituye una labor imprescindible de la Defensoría del Pueblo. Por ello, las leyes de amnistía aprobadas por el gobierno del Ingeniero Alberto Fujimori en la medida que impedían la investigación y juzgamiento de los responsables de graves violaciones a los derechos humanos, constituyeron temas de especial preocupación institucional. Ante esta situación, decidió elaborar un informe en el que se precisó su falta de validez constitucional y las posibilidades existentes para la investigación y juzgamiento de los responsables.

En este contexto, en marzo de 2001, la Corte Interamericana de Derechos Humanos dictó sentencia en el caso "Barrios Altos" condenando al Estado peruano por incurrir en responsabilidad internacional de acuerdo a la Convención Americana sobre Derechos Humanos, señalando que las leyes de "autoamnistía" carecían de efectos jurídicos.

La Defensoría del Pueblo en su Informe Defensorial N. ${ }^{\circ} 57$ "Amnistía vs. Derechos Humanos. Buscando justicia", de 2001, concluyó que: "La sentencia de la Corte Interamericana en el caso Barrios Altos tiene alcance general, debido a la naturaleza normativa del acto violatorio: las leyes N. ${ }^{\circ} 26479$ y N. ${ }^{\circ}$ 26492. Estas leyes al ser incompatibles con la Convención, no pueden serlo sólo en el caso Barrios Altos, sino además con relación a todos los supuestos de violaciones a los derechos humanos en los que ella resulte aplicable. De este modo, la Defensoría del Pueblo considera que para dar cumplimiento a la sentencia de la Corte Interamericana, el Estado peruano, a través del Poder Judicial y el Ministerio Público (...) debería admitir, tramitar denuncias y, de ser el caso, formular denuncia penal, por graves violaciones a los derechos humanos, aún si tales casos se encuentran en los supuestos de hecho de las referidas leyes de amnistía".

De esta manera, a juicio de la Defensoría, se abría la puerta para investigar las graves violaciones cometidas contra los derechos humanos desde la década de los ochenta hasta la actualidad. Para facilitar ello, contaba además con un registro de personas desaparecidas que fue puesto en conocimiento de la Comisión de la Verdad y Reconciliación. Asimismo, ha promovido la investigación sobre los restos humanos encontrados en fosas clandestinas propiciando que sean realizadas por expertos y en base a técnicas y procedimientos adecuados a efectos de alcanzar la verdad ${ }^{23}$.

Cabe indicar que el Decreto Supremo N. ${ }^{\circ}$ 065-2001-PCM creó la Comisión de la Verdad y Reconciliación (CVR) encargada de esclarecer el proceso, los hechos y responsabilidades de la violencia terrorista y de la violación a los derechos humanos (mayo 1980 - noviembre 2000) imputables tanto a las organizaciones terroristas como a los agentes del Estado, así como proponer iniciativas para afirmar la paz y la concordia. La creación de la CVR fue

23 DEFENSORÍA DEL PUEBLO, «Manual para la investigación eficaz ante el hallazgo de fosas con restos humanos en el Perúw, Lima, 2002. 
promovida por la Defensoría del Pueblo y en la actualidad viene desarrollando una labor de seguimiento al cumplimiento de las recomendaciones formuladas, de los cuales da cuenta en sus Informes Defensoriales. Así lo hace, por ejemplo, el reciente Informe Defensorial N. ${ }^{\circ} 139$ "A cinco años de los procesos de reparación y justicia en el Perú. Balance y desafíos de una tarea pendiente".

\subsection{Derechos de las mujeres. Planificación familiar y derechos sexuales y reproductivos}

Desde el inicio de sus funciones, la defensa y promoción de los derechos de las mujeres, ha sido un eje de especial relevancia para el trabajo de la Defensoría del Pueblo. De ahí que se haya promovido la incorporación de la perspectiva de género en todo el desarrollo de la labor defensorial.

Uno de los aspectos abordados ha sido la violencia familiar, particularmente la que afecta a las mujeres. En este campo puede apreciarse que persisten problemas en la aplicación de la ley de protección frente a la violencia familiar. Ello puede apreciarse en el Informe Defensorial N. 144 "Centros Emergencia Mujer: Supervisión de los servicios especializados en la atención de víctimas de violencia familiar y sexual".

De otro lado, se han venido promoviendo reformas en la regulación de los delitos contra la libertad sexual, como por ejemplo, la modificación de aquella disposición que permitía la exención de pena al violador que se casaba con la víctima. Asimismo, la Defensoría ha llamado la atención respecto a la existencia de criterios sexistas de parte de algunos magistrados al momento de resolver los casos llegados a su conocimiento.

Además, se ha llevado a cabo una activa labor de fomento de la participación política de la mujer. En este sentido, destaca la denuncia presentada el 6 de agosto del 2001 por el Defensor del Pueblo y el Movimiento Manuela Ramos ante la Comisión Interamericana de Derechos Humanos contra el Estado peruano, debido a la vulneración de los derechos de participación política de las mujeres en los distritos electorales del Callao, Ica y La Libertad, en los que no se respetó la cuota de 30\% de mujeres en las listas de candidatos durante las elecciones generales del año 2002. Asimismo, podemos mencionar el Informe Defensorial № 122 «La Cuota de Género en el Perú: Supervisión de las elecciones Regionales y Municipales Provinciales 2006”.

Otro tema que motivó la activa intervención de la Defensoría del Pueblo, se presentó cuando el gobierno del Ingeniero Fujimori adoptó una política de planificación familiar, en lo referente a la aplicación de la anticoncepción quirúrgica voluntaria y los derechos sexuales y reproductivos. La Defensoría del Pueblo, verificó que dicho programa presentaba graves irregularidades al no contar con las garantías suficientes de información, prevención y cuidados a la salud de las mujeres. En efecto, se detectó la realización de campañas de anticoncepción quirúrgica, el incumplimiento del periodo de reflexión de 72 
horas, el empleo de formatos no vigentes para la renuncia a dicho plazo, casos de esterilizaciones sin consentimiento, así como de mujeres menores de 25 años, entre otras irregularidades.

Estos casos, motivaron la elaboración de sendos informes defensoriales sobre "La aplicación de la anticoncepción quirúrgica y los derechos reproductivos. Casos investigados por la Defensoría del Pueblo", que tuvieron una trascendencia colectiva y evidenciaron los problemas que se presentaban en los programas de planificación familiar.

Asimismo, desde octubre de 1999, se puso en marcha el sistema defensorial de supervisión del respeto y vigencia de los derechos sexuales y reproductivos que viene siendo aplicado en las distintas Oficinas Defensoriales y que permite la supervisión constante de las políticas sobre planificación familiar.

\subsection{Servicio militar y reforma de la justicia militar}

Desde el inicio de sus funciones se han venido atendiendo numerosas denuncias de levas o reclutamientos irregulares y maltratos cometidos durante el servicio militar. La alternativa, a juicio de la Defensoría del Pueblo, era propiciar un cambio profundo. Ello exigía empezar a discutir qué tipo de fuerzas armadas requería el Perú de cara al próximo milenio. A este esfuerzo se dirigió el Informe Defensorial N. ${ }^{\circ} 22$ denominado "Lineamientos para la reforma del servicio militar: hacia un modelo voluntario", que promovía unas fuerzas armadas profesionales, la reducción del número de reclutas y en ese contexto, un servicio atractivo y voluntario en el marco de una cultura de paz.

Esta propuesta contó con el apoyo del Ejecutivo que a principios de año 1999 anunció el servicio voluntario. Posteriormente, el Congreso de la República aprobó la Ley N. ${ }^{\circ} 27178$ publicada el 29 de setiembre del mismo año que derogó el Decreto Legislativo N. ${ }^{\circ} 264$ - Ley del Servicio Militar Obligatorio- $-\mathrm{y}$ fue un avance respecto al modelo anterior. Ella entró en vigencia el primero de enero del año 2000.

La citada ley acoge la propuesta defensorial de postular un servicio militar voluntario. Sin embargo, para introducirlo a cabalidad debe diseñarse un servicio atractivo, de lo contrario no podrá contarse con el personal requerido. $\mathrm{Y}$ es que en un modelo voluntario, quien presta el servicio lo hace porque así lo desea y no pueden ser obligados - sino convencidos- para hacerlo. Además, para que el servicio sea atractivo, debe eliminarse todo vestigio de maltratos; de lo contrario los jóvenes nunca acudirán voluntariamente. Respecto a estos aspectos la Defensoría permanece vigilante, pues lamentablemente aún subsisten quejas por maltratos en los cuarteles.

De otro lado, la Defensoría del Pueblo desde el inicio de sus funciones ha formulado puntuales recomendaciones al Congreso de la República para modificar la justicia castrense. Así lo hizo en el Informe Defensorial N. ${ }^{\circ} 6$ "Lineamientos para la reforma de la justicia militar en el Perú" (marzo de 1998); 
en el Informe N. ${ }^{\circ} 64$ "La justicia militar en una etapa de transición: Análisis de los proyectos de reforma” (marzo 2002) y en el Informe N. ${ }^{\circ} 66$ "¿Quien juzga qué? Justicia militar vs. Justicia ordinaria" (abril 2003). Así propuso cambios sustantivos a la justicia militar a fin de circunscribirla al juzgamiento de los miembros de las Fuerzas Armadas en actividad que cometan delitos de función o delitos estrictamente castrenses. Asimismo, la revisión de los delitos militares actualmente existentes, a fin de que sólo sean considerados los que materialmente reúnen las características para ser considerados como tales. Igualmente, se ha planteado la necesidad de revisar el diseño orgánico de la justicia militar y su ordenamiento procesal a efectos de garantizar el respeto al debido proceso. Lamentablemente, estos problemas aún subsisten.

\subsection{Libertad de expresión y acceso a la información}

Un aspecto advertido por la Defensoría del Pueblo para evaluar la vigencia de la libertad de expresión es que ella no puede realizarse únicamente con los parámetros utilizados tradicionalmente para encarar esta tarea. Ello porque en vez de antiguos problemas y mecanismos utilizados como la deportación de periodistas, la clausura de medios de comunicación o la censura previa, durante el régimen de Fujimori existieron otros mecanismos menos visibles y más sofisticados con los cuales se obtuvieron similares resultados.

En efecto, en esa época fue posible advertir que junto a la existencia de ciertos medios de prensa escrita y radial críticos al gobierno de entonces, convivieron un conjunto de situaciones y problemas que limitaban sustancialmente la vigencia de la libertad de expresión. Una de las características centrales de este proceso fue la utilización del aparato estatal —incluyendo los servicios de inteligencia - para afectar la libertad de expresión. De un lado, el control a los medios de comunicación se manifestaba a través de las sanciones u hostilizaciones de aquellos medios y periodistas que no estaban dispuestos a aceptar esta situación.

Asimismo, se premiaba económicamente a quienes se mostraban complacientes con la línea periodística impuesta por el gobierno. De esta manera, no existía una información plural, especialmente en la televisión de señal abierta. A ello se unió el permanente seguimiento de los periodistas tanto en forma directa como a través de la interceptación de sus comunicaciones telefónicas. Se utilizó, además, a los propios medios de comunicación — como ciertos canales de la televisión de señal abierta, cierta prensa escrita e incluso una página WEB - para desprestigiar e insultar a periodistas de investigación o aquellos que se mostraban opositores al régimen. Esta situación se agudizó durante las fraudulentas elecciones del año 2000. En la actualidad, estos problemas han sido superados gracias al retorno del régimen democrático.

De otro lado, uno de los temas que se viene promoviendo es la necesidad de alcanzar una cultura de la transparencia —erradicando la cultura del 
secreto- y, en consecuencia, que los funcionarios y servidores públicos brinden la información solicitada y sean considerados como gestores de una organización creada al servicio de la ciudadanía, encontrándose expuestos permanentemente a la fiscalización de la sociedad.

En este sentido, la Defensoría del Pueblo cumplió un activo papel durante el proceso de elaboración de la Ley de Transparencia y Acceso a la Información Pública, efectuando propuestas para contar con una norma que reúna los parámetros básicos que permita alcanzar una cultura de la transparencia. En la actualidad concentra su labor en la atención de casos, la promoción de una cultura de la transparencia y en la supervisión del cumplimiento de la Ley por parte de las entidades del Estado.

\subsection{Acceso y calidad de los servicios públicos}

La Defensoría del Pueblo ha desarrollado actividades tendientes a promover el acceso a servicios públicos de calidad y en condiciones justas y equitativas, entre las que destacan las reuniones de trabajo con organismos del Estado, empresas prestadoras de servicios públicos y asociaciones de consumidores, así como la elaboración de informes que contienen recomendaciones puntuales sobre estos aspectos.

Se ha podido apreciar que los servicios públicos domiciliarios han ampliado significativamente la cobertura de las redes. Sin embargo, ello no alcanza de modo satisfactorio a las zonas rurales ni a las zonas de expansión urbana. Por otro lado, la expansión de redes e instalaciones de los servicios públicos de electricidad y telecomunicaciones se ha desarrollado en ocasiones sin contar con la debida supervisión de las autoridades, por lo que la proliferación de redes instaladas inadecuadamente ha permitido la aparición de puntos de riesgo. En este sentido, podemos mencionar el Informe Defensorial N. ${ }^{\circ} 149$ "La Electrificación Rural en el Perú: Derechos y Desarrollo para Todos", así como el Informe Defensorial N. ${ }^{\circ} 117$ «El Desafío de la telefonía rural: una mirada desde los ciudadanos".

Asimismo, se han aprecia la existencia de avances normativos en cuanto a la transparencia de los organismos reguladores, así como las medidas destinadas a ampliar la participación ciudadana en los procesos de toma de decisiones a través de la publicación de los proyectos de normas y resoluciones de carácter general, la realización de audiencias públicas previas a la adopción de decisiones de carácter regulatorio y la puesta a disposición de la población de las resoluciones expedidas por los organismos reguladores.

En los últimos años, uno de los temas que ha venido abordando es la necesidad de garantizar la seguridad en el servicio público del transporte. Ello se debe, precisamente, a la preocupante cifra de accidentes que se vienen presentando a nivel nacional. 


\subsection{Supervisión Electoral}

La Defensoría del Pueblo viene realizando labores de supervisión electoral desde las elecciones municipales de 1998; posteriormente, hizo lo propio en las generales del 2000 y del 2001. Durante 2002 supervisó las elecciones locales y regionales. Realiza esta función para garantizar el derecho de participación política en condiciones de igualdad, en el marco de su mandato de velar por la defensa de los derechos humanos y supervisar a la administración estatal. Y es que las elecciones constituyen un elemento esencial de toda democracia, la cual proporciona el entorno indispensable para asegurar la protección de los derechos humanos.

Precisamente, para garantizar unas elecciones libres, transparentes y competitivas, la Defensoría investiga las irregularidades que se presentan y exige a las instituciones públicas el correcto cumplimiento de sus funciones. Un aspecto que se ha privilegiado es el respeto del principio de neutralidad, orientado a garantizar la igualdad de oportunidades en la contienda electoral. Ello exige que las autoridades y funcionarios públicos, incluyendo al Presidente de la República, se mantengan neutrales respecto a las opciones políticas en pugna. Asimismo, se ha brindado especial atención a fomentar la participación política de las mujeres, a asegurar facilidades para las personas con discapacidad y garantizar que los pobladores de las comunidades nativas ejerzan sus derechos. Este trabajo se ve reforzado mediante actividades de capacitación, difusión y promoción de vigilancia ciudadana.

El desarrollo de labores de supervisión ha permitido detectar problemas institucionales y normativos que han motivado que la Defensoría del Pueblo promueva la adopción de cambios necesarios en nuestro sistema electoral, a fortalecer a los partidos políticos y a fomentar una cultura política y democrática que garantice que el proceso de afianzamiento de nuestra institucionalidad en el país. Cabe indicar que la intensidad de la actuación de la Defensoría en materia de supervisión electoral ha sido distinta en contextos autoritarios donde los organismos electorales no eran independientes que en los momentos actuales donde vivimos en democracia.

En la actualidad, la labor de supervisión electoral privilegia la exigencia de neutralidad por parte de los funcionarios públicos de los distintos niveles de gobierno - nacional, regional y local— durante los procesos electorales. Se pretende con ello evitar el uso indebido de los bienes y recursos del Estado para favorecer a los candidatos en la contienda electoral. Así por ejemplo, esta FUE la labor principal que viene desarrollando en el actual proceso electoral regional y municipal, que se realizará el 3 de octubre de 2010.

\subsection{Supervisión de políticas públicas y promoción de cambios institucionales}

En los últimos años, la Defensoría ha venido cumpliendo un activo papel en la supervisión de políticas públicas. De esta manera, se viene entendiendo 
que los casos que se presentan no son hechos aislados, sino que responden a un patrón de conducta que requiere de un cambio de la política pública adoptada por el Estado.

Precisamente los informes defensoriales pretenden dar cuenta de las supervisión a las políticas del estado en determinadas materias, y sobre esa base verificar que se respeten los derechos fundamentales. Ello pues lo que se ha venido apreciando es que no basta con atender las quejas individuales que se presentan cotidianamente, sino que resulta indispensable supervisar las políticas públicas y de esa manera aportar al funcionamiento de un Estado que garantice los derechos de las personas.

En este sentido, podemos mencionar, a manera de ejemplos, la supervisión de la vigencia de los derechos a la salud y educación por parte de la Defensoría del Pueblo. Estos resultados se pueden apreciar en el Informe Defensorial N. ${ }^{\circ}$ 105: "El derecho a la salud y a la seguridad social: segunda supervisión nacional", y en el Informe Defensorial N. ${ }^{\circ} 147$ "Aportes de la Defensoría del Pueblo para una Educación sin Corrupción".

En esta materia también destacan los esfuerzos que se vienen desarrollando en promover la reforma del sistema de justicia. Un informe de especial trascendencia fue el Informe Defensorial N. 109 "Propuestas Básicas de la Defensoría del Pueblo para la Reforma de la Justicia en el Perú. Generando consensos sobre qué se debe reformar, quiénes se encargarán de hacerlo y cómo lo harán". Asimismo, en la protección del medio ambiente, donde podemos mencionar el Informe Defensorial N. ${ }^{\circ} 151$ "La Política Forestal y la Amazonía Peruana: Avances y obstáculos en el camino hacia la sostenibilidad", el apoyo a la lucha contra la corrupción y a velar por garantizar la seguridad ciudadana, que se plasmó en el Informe Defensorial N. ${ }^{\circ} 132$ "¿Ciudadanos desprotegidos?: Estrategias para fortalecer el Sistema Nacional de Seguridad Ciudadana"

\subsection{Prevención de conflictos sociales}

Como la propia Defensoría del Pueblo ha señalado, ella "ha intervenido en conflictos sociales prácticamente desde su creación; sin embargo, la complejidad del problema requería incrementar las capacidades institucionales para la comprensión multidisciplinaria de este fenómeno, diseñar estrategias de intervención y capacitar al personal en la materia ${ }^{24}$.

Por ello, en junio de 2005 a través de la Resolución Administrativa N. ${ }^{\circ}$ 030-2005/DP, se formalizó la existencia del Comité de Seguimiento e Intervención en Conflictos Sociales y Políticos. Posteriormente, se creó la Unidad de Conflictos Sociales que luego, en abril de 2009, pasaría a convertirse en la Adjuntía para la Prevención de Conflictos Sociales y la Gobernabilidad.

24 DEFENSORÍA DEL PUEBLO, "Ante todo, el diálogo. Defensoría del Pueblo y conflictos sociales y políticos", Lima: Defensoría del Pueblo, 2005, p19. 
En esta dirección, la Defensoría brinda atención, seguimiento y análisis a los conflictos sociales a nivel nacional, los cuales suelen ser clasificados como conflictos activos, latentes, reactivados y resueltos. Esta labor se ve facilitada debido a la presencia nacional de la institución. Asimismo, elabora reportes que son información fundamental para la toma de decisiones.

"Esta tarea permanente ha permitido que el Reporte de conflictos sociales de la Defensoría del Pueblo se consolide como un documento básico de referencia en materia de conflictividad social en el país. Además, este trabajo se ve reforzado mediante la difusión permanente de información especializada sobre conflictos sociales a través del portal web de la Defensoría del Pueblo, específicamente en los boletines diarios Conflictos al dia y Cronología de los conflictos, y el Reporte mensual. Estos documentos presentan la información de una manera ágil y accesible a la ciudadanía en general, ${ }^{25}$.

Se trata de información de especial relevancia para poder evaluar y prevenir los diversos conflictos sociales que se vienen presentando en el país, que ninguna otra entidad pública realiza con el detalle que caracteriza a los reportes de la Defensoría.

\subsection{Intervención en procesos constitucionales}

El artículo 203 inciso 3) de la Constitución reconoce a la Defensoría del Pueblo legitimación para interponer acciones de inconstitucionalidad. Asimismo, su ley orgánica, Ley 26520, al igual que en España, Argentina, Bolivia, Colombia, Costa Rica, El Salvador, Nicaragua, Panamá, Venezuela, entre otros ordenamientos jurídicos ${ }^{26}$, concede al Defensor del Pueblo legitimación para iniciar e intervenir en los procesos de hábeas corpus, amparo, hábeas data, acción de cumplimiento y acción popular. En este sentido, el artículo 9 inciso 2) de la Ley N. 26520, señala que el Defensor del Pueblo está facultado para:

"Ejercitar ante el Tribunal Constitucional la acción de inconstitucionalidad contra las normas con rango de ley a que se refiere el inciso 4) del Artículo $200^{\circ}$ de la Constitución Política, asimismo, para interponer la acción de hábeas corpus, acción de amparo, acción de hábeas data, la de acción popular y la acción de cumplimiento, en tutela de los derechos constitucionales y fundamentales de la persona y de la comunidad.

Asimismo, está capacitado o facultado para intervenir en los procesos de hábeas corpus, para coadyuvar a la defensa del perjudicado".

Por su parte, el Código Procesal Constitucional (Ley 28237, publicada el 31 de mayo del 2004), vigente desde el 1 de diciembre del 2004, también re-

25 Defensoría del Pueblo, Décimo Tercer Informe Anual de la Defensoría del Pueblo al Congreso de la República enero - diciembre 2009, pág. 244.

26 SANTISTEVAN DE NORIEGA, J., "El Defensor del Pueblo en Iberoamérica", en "Comentarios a la Ley Orgánica del Defensor del Pueblo", VVAA Defensor del Pueblo, Aranzadi, 2002, pág. 981. 
conoce legitimación a la Defensoría del Pueblo en los procesos de hábeas corpus (artículo 26), amparo (artículo 40), hábeas data (artículo 65), cumplimiento (artículo 67), popular (artículo 84) e inconstitucionalidad (artículo 98).

Tal legitimación potencia la actividad de la Defensoría del Pueblo pues ante el incumplimiento de sus recomendaciones o exhortaciones se convierte en un instrumento adicional que acrecienta la posibilidad de lograr que sus conclusiones respecto a la violación de determinados derechos o principios constitucionales sean cumplidas ${ }^{27}$. Se trata, como lo afirma la teoría procesal de un supuesto de legitimación procesal extraordinaria ${ }^{28}$, pues no obedece a la clásica legitimidad vinculada a la defensa de un derecho subjetivo, sino que se explica en tanto posibilita que un órgano constitucional pueda cumplir adecuadamente sus funciones de defensa de los derechos y principios constitucionales. En estos casos la Defensoría del Pueblo actúa en nombre "de la misma sociedad que impone a los poderes públicos la obligación de que sean celosos en el respeto y efectivo cumplimiento de los derechos fundamentales. ${ }^{29}$

A lo largo de su funcionamiento, la Defensoría del Pueblo ha decidido intervenir en un limitado número de casos, pues ha considerado que se trata de una facultad que debe ser utilizada en forma excepcional y subsidiaria. Precisamente, para definir si debe intervenir o no en un determinado proceso constitucional se han ido elaborando una serie de criterios a lo largo de su funcionamiento en consideración a la naturaleza de esta institución y la experiencia comparada a fin de hacerlo en aquellos casos en que realmente se justifique ${ }^{30}$. Entre estos criterios podemos mencionar: a) el hecho que no exista otra vía posible para garantizar los derechos fundamentales o el principio de supremacía constitucional, pues se han agotado todos los medios razonablemente existentes para ello. Así por ejemplo, antes de interponer una demanda de inconstitucionalidad se suele exhortar al órgano que dictó la norma cuestionada para que la derogue o modifique a fin de que pueda rectificarse, salvo que se requiera una actuación de urgencia; b) la clara y manifiesta violación de derechos o principios constitucionales por parte del acto o norma que se cuestiona. Y es que ante la falta de claridad y convicción sobre la amenaza o vulneración de derechos o principios constitucionales, se prefiere

27 PIZA ESCALANTE R., "El Defensor de los Derechos Humanos frente a la justicia constitucional", Memoria del Primer Congreso de la Federación Iberoamericana de Defensores del Pueblo, Procuradores, Comisionados y Presidentes de Comisiones Públicas", México: Comisión Nacional de Derechos Humanos, 1996, págs. 49 y ss.

28 MONTERO AROCA J., "Derecho Jurisdiccional", Tomo II. J.M. Bosch Editor, Barcelona, 1991, pág.36.

29 GIMENO SENDRA V., y GARBERI LLOBREGAT J., "Los procesos de amparo”, Madrid: Colex, 1994, pág.170.

30 En España desde el primer informe presentado a las Cortes Generales (1983) se formularon puntuales criterios de intervención. Cfr. Defensor del Pueblo, Informe a las Cortes Generales 1983, págs. 26-27. Defensor del Pueblo, Recursos ante el Tribunal Constitucional 19831987, pág. VI. 
abstenerse de ejercer su facultad discrecional de interponer la demanda respectiva o intervenir en un proceso constitucional ya iniciado. c) la situación de indefensión de las personas que se vean afectadas por la norma o la decisión cuestionada, pues no se pretende sustituir a las partes ni convertirse en un abogado de oficio, d) la trascendencia colectiva que subyace a la controversia constitucional planteado que puede contribuir a fijar un precedente que incida en otros casos,

De esta manera, se ha intervenido en aquellos casos en los cuales no encontraba otra forma de resolver un problema de afectación a derechos o principios constitucionales que le había sido planteado.

Una de las demandas que tuvo un gran impacto fue la que se interpuso contra el segundo párrafo del artículo 191 de la Ley Orgánica de Elecciones que prohibía la difusión de resultados no oficiales desde las cuatro de la tarde hasta un máximo de seis horas. Dado que esta norma limitaba las libertades de expresión e información pues impedía la difusión de información y el acceso a ella, la Defensoría del Pueblo presentó el 7 de marzo del 2001 una acción de inconstitucionalidad ante el Tribunal Constitucional para que éste la deje sin efecto. Ante este pedido, el Tribunal (Exp. N. ${ }^{\circ}$ 002-2001-I/TC) declaró inconstitucional la norma cuestionada. El 5 de abril se publicó la sentencia en el diario oficial y a partir del día siguiente el dispositivo dejó de existir. De esta manera, se contribuyó a la vigencia de las libertades de expresión, información y a la transparencia del proceso electoral. Ello permitió a todos los ciudadanos y ciudadanas estar informados develando el "silencio de seis horas» impuesto por una disposición fruto de circunstancias muy distintas a las actuales.

Asimismo, la Defensoría del Pueblo presentó una demanda de inconstitucionalidad contra diversos artículos de la Ley Orgánica de Justicia Militar, del Código de Justicia Militar y de la Ley del Ministerio de Defensa, para que adecue la legislación penal militar a los parámetros constitucionales y las obligaciones del Estado en materia de derechos humanos. La Defensoría solicitó al Tribunal Constitucional que declare la inconstitucionalidad del modelo vigente de justicia militar, que en lo esencial mantiene el esquema del primer Código de Justicia Militar de 1898. En junio del 2004, en una histórica sentencia, publicada el 30 de octubre del mismo año, el Tribunal Constitucional (Exp. N. ${ }^{\circ}$ 023-2003-AI/TC) declaró fundada en parte la demanda interpuesta. Entre otras consideraciones, sostuvo que el hecho que los jueces militares sean oficiales en actividad designados por el Poder Ejecutivo afectaba la autonomía e independencia que debe caracterizar a todo magistrado.

Agregó que las normas cuestionadas no garantizaban la inamovilidad con la que debe contar todo juez y que el diseño del Ministerio Público militar, que forma parte de la justicia castrense, no se ajustaba a lo dispuesto por la Constitución que reconoce a dicho órgano autonomía e independencia. De esta manera, el Tribunal declaró inconstitucional el propio diseño de la justicia militar. Asimismo, señaló que los tribunales militares se encargan de sancionar delitos de función y que no es su finalidad esencial e inmediata velar 
por el mantenimiento de la moral, orden y disciplina, conceptos que, además, son ambiguos. Precisó que los tribunales militares jamás pueden juzgar delitos contra los derechos humanos, los cuales son imprescriptibles. Lamentablemente, el Congreso no hizo caso de esta sentencia y dictó una nueva norma en términos similares y una nueva conformación del Tribunal Constitucional la convalidó.

\section{REFLEXIONES FINALES}

Las Defensorías del Pueblo son instituciones relativamente jóvenes en América Latina que aparecen para garantizar los derechos de las personas y los principios democráticos. Si bien se han inspirado en modelos europeos, el especial contexto de América Latina caracterizado por la debilidad del sistema democrático y las afectaciones a los derechos humanos, ha hecho que tengan que adaptarse para poder cumplir a cabalidad su misión.

Por ello, resulta evidente que el contexto en el cual las Defensorías del Pueblo se desenvuelven es determinante para definir la "agenda" de temas y líneas de trabajo que deben priorizar para cumplir cabalmente su misión de defensa de los derechos humanos y de consolidación del sistema democrático.

Para que esto suceda es fundamental que la institución tenga autonomía e independencia respecto del poder político, cuestión indispensable en contextos autoritarios o en dictaduras. Y es que una Defensoría del Pueblo puede limitarse a tramitar los casos que recibe y "Sobrevivir", u optar por actuar de oficio frente a los aspectos que considera constituyen las causas estructurales de los problemas de un país. De ahí que consideremos que una Defensoría del Pueblo "activista" y "garantista" tendrá una visión distinta y planificará sus objetivos estratégicos y líneas de trabajo para instaurar una cultura de respeto a los derechos frente al poder. El reto es no llegar a excesos que puedan convertir a la institución en un "activista político" que pretenda reemplazar a los partidos de oposición, olvidando su papel de entidad supervisora del respeto a los derechos humanos por parte de todas las entidades públicas. Asimismo, hay que evitar que el Defensor pueda pensar que tan pronto culmine su mandato puede tentar a un cargo de elección popular, a fin de evitar posibles suspicacias que debiliten a la institución o que pueda actuar con fines distintos.

Como se sabe, las Defensorías del Pueblo no tienen poderes coercitivos. Por ello, es importante su legitimidad, credibilidad y conocimiento para persuadir o convencer que sus recomendaciones son acertadas, razonables y suficientemente motivadas. Pese a que en los países de América Latina suele suceder que si no hay sanción la ley no se cumple, las Defensoría vienen demostrando que es posible convencer sin imponer. De ahí que se pueda hablar de la "fortaleza de la persuasión".

En Perú, trasla crisis política que condujo a la huida del país y la declaración de vacancia del ex-Presidente Alberto Fujimori como Presidente de la 
República, así como de la elección del Presidente Valentín Paniagua durante la etapa de transición y de sus sucesores, los Presidentes Alejandro Toledo y Alan García se ha abierto un nuevo espacio de intervención de la Defensoría del Pueblo destinado a promover la democracia a y apoyar los cambios institucionales necesarios que contribuyan a garantizar la gobernabilidad en el país.

Cabe distinguir así tres etapas de la Defensoría del Pueblo en el Perú. La primera, durante el régimen autoritario de Fujimori fue una época sumamente difícil pues sus espacios de actuación se reducían por la ausencia del un gobierno democrático. No obstante, durante dicha etapa la Defensoría se consolidó y obtuvo niveles de legitimidad impresionantes, convirtiéndose en la única institución pública independiente. Una segunda etapa, se presentó durante la transición democrática y la actual se presenta con mayores espacios de actuación fruto de vivir en un régimen democrático. Por ello, la primera ha sido una etapa fundamental para el desarrollo de la Defensoría del Pueblo en el Perú.

A lo largo de sus catorce años de funcionamiento la Defensoría del Pueblo ha podido detectar un conjunto de problemas estructurales en los cuales ha venido interviniendo y que constituyen la agenda básica de su actuación defensorial, a efectos que los poderes públicos puedan asumir estos retos y sobre esa base poder garantizar los derechos humanos y la institucionalidad democrática. Como lo ha afirmado la Defensoría del Pueblo, el control defensorial cuenta con una doble función. De un lado resolver los casos concretos que llegan a su conocimiento tanto a iniciativa de parte o de oficio; y de otro, velar por la promoción y defensa de la legalidad democrática como marco esencial para la vigencia de los derechos ciudadanos. Para cumplir esa labor, a lo largo de los años, ha ido adecuando su estructura orgánica, incrementando su presencia a nivel nacional y fortaleciendo sus instrumentos de gestión. Todo ello, en última instancia con el objetivo de garantizar los derechos de las personas.

TitLE:The Ombudsman. The peruvian experience.

ABSTRACT: This article examines the introduction of the Peruvian Office of the Ombudsman in the 1993 Constitution, its legal development and its operation since the official start of its activities in 1996 up to now. There have been three phases in the performance of the Office of the Ombudsman in Peru. The first, during the regimen of President Fujimori, when their performance spaces were reduced due to the absence of a democratic government. However, during this phase the Office of the Ombudsman was consolidated and obtained impressive levels of legitimacy, becoming the only independent public institution. A second phase occurred during the democratic transition. The third one has a good enviroment to carry-out its activities as a result of living in a democratic. goverment.The Office of the Ombudsman has identified a set of structural problems which form the basic agenda of their performance. This has allowed it to consolidate its public legitimacy. 
Resumen: El presente artículo examina la introducción de la Defensoría del Pueblo en la Constitución peruana de 1993, su desarrollo normativo, asi como su funcionamiento desde el inicio oficial de sus actividades (1996) hasta la actualidad. Han existido tres etapas de la Defensoria del Pueblo en el Perú. La primera, durante el régimen del ex-Presidente Alberto Fujimori, fue muy difícil pues sus espacios de actuación eran reducidos debido a la ausencia de un gobierno democrático. No obstante, durante dicha etapa la Defensoría se consolidó y obtuvo niveles de legitimidad impresionantes, convirtiéndose en la única institución pública independiente. Una segunda etapa, se presentó durante la transición democrática y la actual se presenta con mayores espacios de actuación fruto de vivir en un gobierno democrático. La Defensoría del Pueblo ba detectado un conjunto de problemas estructurales en los cuales ha venido interviniendo y que constituyen la agenda básica de su actuación. Todo ello le ha permitido ir consolidando su legitimidad ciudadana.

KeYwords: Peruvian Office of the Ombudsman. Activities. Election. Agenda. Problems.

Palabras clave: Defensor del Pueblo peruano. Actvidades. Elección. Agenda. Problemas.

FECHA DE RECEPCIÓN: 17.06.2010. FeCHA DE ACEPTACIÓN: 28.07.2010. 